\title{
Gender Differences in Perceived Illness, Stress, and Coping in Undergraduates
}

\author{
Corrine Wilsey, Jennifer A. Lyke \\ Stockton University, New Jersey, USA
}

\begin{abstract}
The study was designed to explore gender differences in perceived illness, stress level, and coping style. Participants were 236 male and female undergraduates who completed surveys assessing their experienced stressors, coping style, and number of illnesses experienced in the past 12 months. Negative coping, stress, and gender were significant predictors of differences between participants with high and low levels of self-reported physical symptoms. In addition, discriminant function analyses indicated that negative coping was associated with high or low level of illness for both genders, but stress was also a significant predictor for females. Limitations and implications of the findings are discussed.
\end{abstract}

Keywords: gender, stress, coping, illness, undergraduates

\section{Introduction}

Several studies have found gender differences in both mental and physiological health measures, such as depression, anxiety, and physical illness (Barnett, Biener, \& Baruch, 1987; Mirowsky \& Ross, 1995). These differences are difficult to explain due to the variety of biological, psychological, and social factors that affect the physical and emotional experiences of men and women. However, it is important to identify how gender relates to health and illness in order to target prevention and treatment strategies most effectively.

\section{Stress and IIlness}

It is well established that psychological stress weakens the functioning of the immune system and makes people more susceptible to illness (e.g., Cohen, Miller, \& Rabin, 2001). However, less research has investigated how this relationship may operate differently in men and women. One notable exception is a study by Matheny, Ashby, and Cupp (2005), who investigated stress, coping, and illness among 187 graduate students. Results indicated an important difference between men and women in the factors associated with physical illness. Specifically, these researchers found that coping effectiveness is more important than life-changing events in predicting illness among men, whereas both factors are important in predicting illness among women. Further, they also found that women had significantly more coping skills than men, but they also reported more illness than men. As a result of this paradoxical finding, Matheny et al. (2005) proposed that illness may actually be used as a coping mechanism for women. It could be a way to recruit others' help and support, and it is possible that illness, especially of a minor nature, may be a woman's way of unconsciously giving herself permission to take care of and pay attention to her own needs. Thus, understanding the role of gender in the relationship 
between stress and illness is an important consideration as research in this area progresses.

\section{Stressors}

Another important consideration is that men and women experience different kinds of stressors and different amounts of stress in their lives (McDonough \& Walters, 2001; Mirowsky \& Ross, 1995). For example, in a study of 2,816 people, Matud (2004) found that women experience more chronic stress and daily stressors than men and report more psychological distress and somatic symptoms than men. Similarly, Turner, Wheaton, and Lloyd (1995) conducted face-to-face interviews with 1,393 adults, and also found that women reported significantly higher levels of recent and ongoing stress as well as more depressive symptoms compared to men. These differences apparently begin in adolescence (Jose \& Ratcliffe, 2004), further complicating the relationship between gender, stress, and illness.

The physical symptoms associated with stress are certainly influenced by the physical body in which they manifest. On a physiological level, it has been established that men and women have different responses to stress (Schmaus, Laubmeier, Boquiren, Herzer, \& Zakowski, 2008), and coping strategies under stress also may have different physical consequences for men and women (Flynn, Schipper, Roach, \& Segerstrom, 2009). Thus, both stressors and coping strategies may influence gender differences in physical symptoms associated with stress and may in part explain the discrepancy between the frequency of stress-related illness in men and women.

The difference between men's and women's social roles is another important factor that affects the relationship between stress and gender (Aneshensel, Frerichs, \& Clark, 1981; Cleary \& Mechanic, 1983). For example, women report family- and health-related events experienced by themselves and those in their environment as more stressful compared to men (Stein \& Nyamathi, 1999) whereas men report work events experienced by themselves as highly stressful (Matud, 2004). Perhaps women are affected more by the stress experienced by those around them because they tend to be more emotionally involved in social and family networks than men (Kessler \& McLeod, 1984; Turner et al., 1995). In other words, a person's social role may affect both the nature and perceptions of his or her experiences.

Subjectively, even when men and women experience the same stressors, they may have different reactions. For example, Matud (2004) found that women evaluate threatening situations as more stressful than men. In terms of extreme stress, it is well known that men experience traumatic events more often than women, and men and women tend to experience different types of traumatic events. However, women are more likely than men to develop post-traumatic stress disorder after experiencing a traumatic event (Gavranidou \& Rosner, 2003). This result could be due to the fact that women experience events as more stressful than men, which could make them more prone to developing post-traumatic stress disorder.

\section{Coping}

Coping style plays an important role in mediating between a stressful experience and the psychophysiological reactions to that experience, but research into the relationship between gender and coping style has produced mixed results. Some researchers have found no consistent differences between men's and women's coping styles (Pritchard \& Wilson, 2006; Hamilton \& Fagot, 1988), while others have found that women use more emotion-focused coping strategies whereas men use more problem-focused strategies (Miller \& Kirsch, 1987; Matud, 2004; Folkman, Lazarus, Dunkel-Schetter, Delongis, \& Gruen, 1986; Day \& Livingstone, 2003). In general, problem-focused coping has been found to be more effective than 
emotion-focused coping, which is associated with psychological distress (Sigmon, Stanton, \& Snyder, 1995).

This study was designed to explore gender differences in self-reported physical symptoms, stress levels and coping style in undergraduates, who, as a group, are acknowledged to experience high degrees and frequencies of stress. It was hypothesized that there would be significant differences in the relationship among stressors, coping styles, and illnesses for men and women.

\section{Method}

\section{Participants}

Participants were 55 male and 181 female undergraduates recruited from college classes, predominantly in the social and behavioral sciences, at a mid-size public college in the Mid-Atlantic region. Most students received extra credit for their participation but there was no financial incentive offered.

\section{Instruments}

Experienced Illness Survey. This measure was created by modifying SIRS (the Seriousness of Illness Rating Scale) (Wyler, Masuda, \& Holmes, 1968), a scale ranking the seriousness of various physical illnesses according to medical professionals. The original scale included 126 diseases. The Experienced Illness Survey was created by extracting a subset of 24 conditions judged most likely to be related to stress and present in a college population, such as "headache", "common cold", and "nose bleed". In addition, diseases unlikely to occur in a college population were eliminated, such as "smallpox" and "hardening of the arteries." Instructions asked participants to indicate which of the 24 conditions they had experienced during the last year. The number of conditions participants reported produced the variable TI (total illnesses). Illnesses reported were then weighted according to the seriousness rankings assigned in the original research to produce the variable TWI (total weighted illnesses).

College Undergraduate Stress Scale. CUSS (the College Undergraduate Stress Scale) (Renner \& Mackin, 1998) assesses participants' self-reported stress experienced during the last year. It includes a list of 51 stressful events commonly experienced by college students, such as "oversleeping for an exam", and asks participants to report whether or not they have experienced the event. Each event is assigned a score from 20 to 100 based on its perceived stressfulness. Numbers representing the amount of stress associated with each event were then added to produce a total stress score.

Brief COPE. The Brief COPE (Carver, 1997) is a 28-item self-report inventory used to measure participants' use of 14 coping strategies: self-distraction, active coping, denial, substance use, emotional support, instrumental support, behavioral disengagement, venting, positive reframing, planning, humor, acceptance, religion, and self-blame. Participants respond to statements such as "I've been getting emotional support from others" on a scale from one ("I haven't been doing this at all") to eight ("I've been doing this a lot"). Participants were asked to report how they have responded to stressful events they have experienced in the past year, and their responses were added to produce a total score for their coping behavior (Total COPE). Participants' scores on individual items were then grouped into three subscales based on a factor analysis of the data set as recommended by Carver (1997). The three subscales produced by this data set were Positive Coping (self-distraction, active coping, positive reframing, planning, and humor), Negative Coping (denial, substance use, behavioral disengagement, venting, and self-blame), and External Support (emotional support, instrumental support, and religion). 


\section{Procedure}

The instruments were distributed to students in a variety of college classes or through an online system for research participation, and were self-administered. No surveys were completed during class time. The surveys that were completed on paper were submitted to the students' professors, who returned them to one of the authors. The surveys that were completed online were retrieved by one of the authors.

\section{Results}

\section{Descriptive Statistics}

A total of 236 participants were surveyed. The sample was $77 \%$ female and $23 \%$ male. The mean age for participants was 22.04 years $(S D=4.64)$. The sample was $81 \%$ Caucasian, 6.2\% Hispanic, 5.5\% Black African-American, 4.1\% Asian, and 2\% Other.

The sample reported a range of 0 to 19 total illnesses during the last year $(M=7.77, S D=3.29)$. After weighting the illnesses according to seriousness, the weighted illnesses for the sample ranged from zero to 4,653 $(M=1440.62, S D=959.65)$. CUSS scores for the sample ranged from 408 to $2,421(M=1460.81, S D=$ 348.94). Total COPE scores ranged from 28 to $99(M=67.17, S D=13.26)$, with Positive Coping ranging from 12 to $47(M=33.01, S D=7.25)$, Negative Coping ranging from 10 to $37(M=19.31, S D=5.78)$, and External Support ranged from six to $24(M=14.85, S D=4.52)$. Intercorrelations among the study variables are presented in Table 1. Descriptive statistics for each of the variables by gender are presented in Table 2.

Table 1

Intercorrelations Among Study Variables

\begin{tabular}{|c|c|c|c|c|c|c|c|}
\hline & TI & TWI & CUSS & Total COPE & $\begin{array}{l}\text { Positive } \\
\text { coping }\end{array}$ & $\begin{array}{l}\text { Negative } \\
\text { coping }\end{array}$ & $\begin{array}{l}\text { External } \\
\text { support }\end{array}$ \\
\hline TI & -- & & & & & & \\
\hline TWI & $0.917^{* *}$ & -- & & & & & \\
\hline CUSS & $0.512^{* *}$ & $0.468^{* *}$ & -- & & & & \\
\hline Total COPE & $0.269^{* *}$ & $0.289^{* *}$ & $0.285^{* *}$ & -- & & & \\
\hline Positive coping & 0.098 & 0.107 & $0.143^{*}$ & $0.846^{* *}$ & -- & & \\
\hline Negative coping & $0.441^{* *}$ & $0.472^{* *}$ & $0.421^{* *}$ & $0.674^{* *}$ & $0.293^{* *}$ & -- & \\
\hline External support & 0.068 & 0.072 & 0.067 & $0.716^{* *}$ & $0.503^{* *}$ & $0.229^{* *}$ & -- \\
\hline
\end{tabular}

Notes. TI $=$ Total illnesses; TWI $=$ Total weighted illnesses $;{ }^{*} p<0.05 ;{ }^{* *} p<0.001$.

Table 2

Means, SDs and Independent Samples t-Test for Variable Scores by Gender

\begin{tabular}{|c|c|c|c|c|c|c|}
\hline \multirow{2}{*}{ Scale } & \multicolumn{2}{|c|}{ Males $(N=55)$} & \multicolumn{2}{|c|}{ Females $(N=181)$} & & \multirow{2}{*}{$p$} \\
\hline & $M$ & $S D$ & $M$ & $S D$ & & \\
\hline TI & 6.38 & 2.66 & 8.19 & 3.35 & -3.67 & 0.000 \\
\hline TWI & 1012.38 & 723.74 & 1570.75 & 985.97 & -3.37 & 0.001 \\
\hline CUSS & 1396.93 & 328.86 & 1480.22 & 353.40 & -1.55 & 0.121 \\
\hline Total COPE & 62.00 & 14.51 & 68.74 & 12.48 & -3.37 & 0.001 \\
\hline Positive coping & 31.51 & 8.11 & 33.47 & 6.93 & -1.76 & 0.079 \\
\hline Negative coping & 17.89 & 5.69 & 19.74 & 5.75 & -2.09 & 0.037 \\
\hline External support & 12.60 & 4.36 & 15.53 & 4.39 & -4.37 & 0.000 \\
\hline
\end{tabular}




\section{Discriminant Function Analysis}

Discriminant function analysis was used to determine which variables discriminated between groups with high and low levels of perceived illness. The initial analysis sought to determine whether gender, stress, and/or coping styles were significant determinants of whether participants were above or below the median level of perceived illness. Negative coping, stress and gender were significant predictors of differences between participants with high and low levels of self-reported physical symptoms (see Table 3 ).

Follow-up analyses were then performed to investigate whether stress and/or coping styles related to illness groups differently for each gender. The median TWI for men was 890 and for women was 1,416. Men and women were coded into high and low illness groups according to these cutoff scores. Discriminant function analysis for males indicated that only negative coping was associated with illness group (Wilks' $\Lambda=0.865, F(1$, $53)=8.28, p<0.01)$. However, for females, stress was a significant predictor along with negative coping $($ Wilks' $\Lambda=0.780, F(1,178)=25.06, p<0.001)$. Results for men and women separately are presented in Table 4.

Table 3

Discriminant Function Analysis of Illness Groups for Total Sample

\begin{tabular}{|c|c|c|c|}
\hline Step & Variables entered & Wilks' $\Lambda$ & $p$ \\
\hline 1 & Negative coping & 0.843 & 0.000 \\
\hline 2 & Stress & 0.780 & 0.000 \\
\hline 3 & Gender & 0.764 & 0.000 \\
\hline \multicolumn{4}{|c|}{ Canonical discriminant function } \\
\hline Canonical correlation & Wilks' & & $p$ \\
\hline 0.486 & 0.764 & & 0.000 \\
\hline \multicolumn{4}{|c|}{ Pooled within-groups correlations between canonical discriminant functions and discriminating variables } \\
\hline Discriminating variables & & Function 1 & \\
\hline Negative coping & & 0.586 & \\
\hline Stress & & 0.572 & \\
\hline Gender & & 0.294 & \\
\hline Box's $M$ & \multicolumn{2}{|c|}{ Approximate $F$} & $p$ \\
\hline 12.681 & 2.084 & & 0.052 \\
\hline
\end{tabular}

Table 4

Discriminant Analysis of Illness Groups for Males and Females Separately

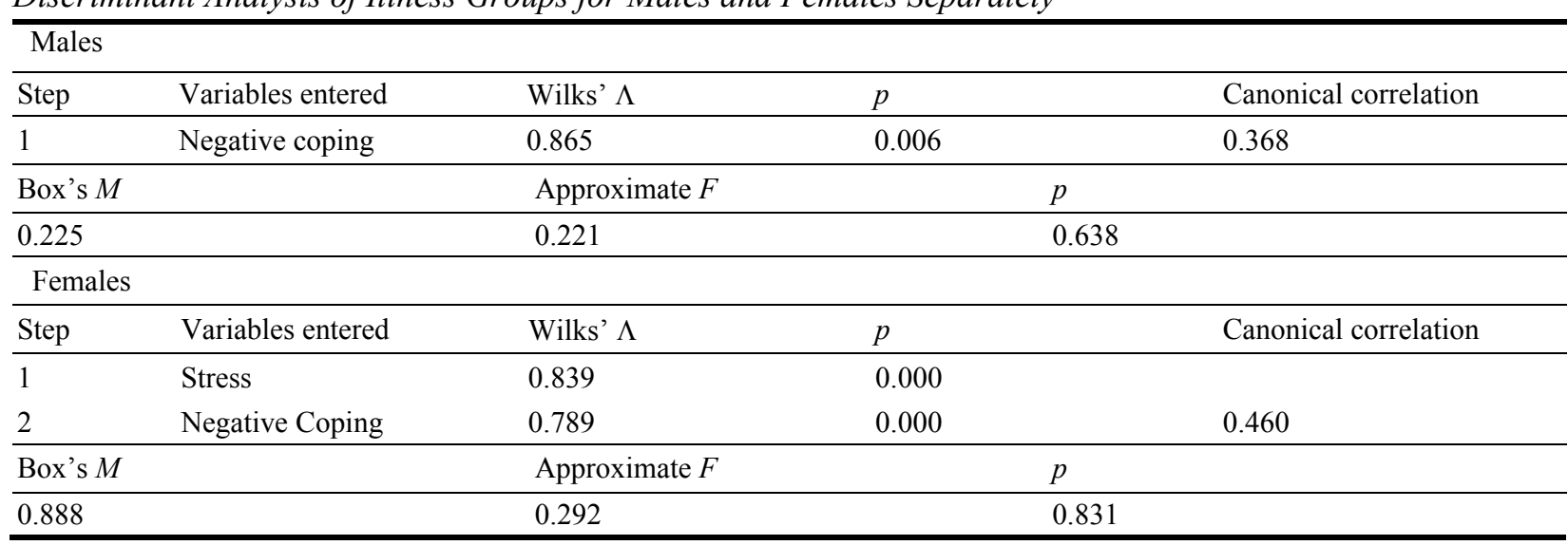




\section{Discussion}

The only predictor of illness shared by both sexes was negative coping style. For men, it was the only predictor of illness. For women, negative coping style combined with the stress they are experiencing was the greatest predictor of illness. Stress did not appear to be a factor in predicting illness in men. These findings differ from those of Matheny et al. (2005), whose study of graduate students focused on coping behaviors rather than coping style, and concluded inadequate coping resources put both sexes at risk of illness. These findings further differ from those of other studies, some of which have suggested that gender differences in stress and coping among university students may be diminishing as social changes in genders take place over time (Matud, 2004). Matud's (2004) study, administered to a larger and more diverse sample of people ranging in age from 18 to 65, used different stress measurements that included life events, a broader measure than that used on college undergraduates whose stressors are specific to that population.

Results indicated that college-aged women report such physical symptoms as headache, dizziness, fainting, hyperventilation, migraine, irregular heartbeat, depression, nervous breakdown, and being overweight significantly more frequently than men. In addition, there was no illness that men reported more frequently than women, which may support the conclusion that illness serves as coping function in women (Matheny et al., 2005).

The three illnesses that differed significantly in frequency between men and women, depression, nervous breakdown, and being overweight, may complicate this conclusion. Forty-one percent of women in the sample reported being depressed compared to only $18 \%$ of men, which is consistent with the vast literature documenting greater prevalence of depression in women than men. However, both of these rates are well above the rates expected given estimates based on clinical interviews of other populations (Kessler, Chiu, Demler, \& Walters, 2005). Therefore, it is reasonable to assume that participants were using the more casual definition of depression, which describes a generally low mood. Given that limitation, the results of this study do reflect the 2:1 ratio for women to men that is commonly reported in the literature, indicating that depression may be one of the symptoms that is particularly likely to manifest in women, as opposed to men, who are stressed.

"Nervous breakdown" is another symptom of illness that is problematic since it is a commonly used term but not technically defined as a medical condition. The SIRS item used to derive the Experienced Illness Survey specifically defined a nervous breakdown as "heavy emotional distress causing difficulty to function in daily life", and this definition was provided to participants. Approximately six times as many women as men $(41 \%$ vs. $7 \%)$ in this sample reported having experienced a nervous breakdown during the last year, indicating debilitating emotional distress is much more likely to be experienced by women than men regardless of their level of stress or the amount of coping strategies they employ.

Finally, the symptom of "being overweight" is a concern because it is so subjectively judged and context dependent. An extensive literature relating gender and body image disturbance has shown that women are much more likely to judge their bodies critically than men. Therefore, this is another illness that may not have been reported accurately by participants. Specifically, the frequency of women reporting that they have been overweight during the last year may have been inflated by social factors that differentially affect women's self-perception. On the other hand, it is also well known that women are more likely to develop symptoms of eating disorders, which potentially result in becoming overweight (Striegel-Moore et al., 2009).

The solution to these shortcomings in future research would be to incorporate more objective measurements of the illness symptoms described in the Experienced Illness Survey. Future work could also 
identify ways emotional distress contributes to the relationship between illness and gender.

This study attempted to replicate the findings of Matheny et al. (2005) with an undergraduate population as opposed to a graduate student population. If the study of Matheny et al. (2005) had been replicated, it could be generalized to a broader college population.

Overall, these results indicate that gender is as an important factor that relates independently to the experience of physical symptoms in college students beyond the ways in which it is associated with stress and coping.

\section{References}

Aneshensel, C. S., Frerichs, R. R., \& Clark, V. A. (1981). Family roles and sex differences in depression. Journal of Health and Social Behavior, 22, 379-393.

Barnett, R. C., Biener, L., \& Baruch, G. K. (1987). Gender \& stress. New York: The Free Press.

Carver, C. S. (1997). You want to measure coping but your protocol's too long: Consider the Brief COPE. International Journal of Behavioral Medicine, 4, 92-100.

Cleary, P. D., \& Mechanic, D. (1983). Sex differences in psychological distress among married people. Journal of Health and Social Behavior, 24, 111-121.

Cohen, S., Miller, G. E., \& Rabin, B. S. (2001). Psychological stress and antibody response to immunization: A critical review of human literature. Psychosomatic Medicine, 63, 7-18.

Day, A. L., \& Livingstone, H. A. (2003). Gender differences in perceptions of stressors and utilization of social support among university students. Canadian Journal of Behavioural Science, 35(2), 73-83.

Flynn, S. M., Schipper, L. J., Roach A. R., \& Segerstrom, S. C. (2009). Gender differences in delayed-type hypersensitivity response: Effects of stress and coping in first-year law students. Brain, Behavior, and Immunity, 23, 672-676.

Folkman, S., Lazarus, R. S., Dunkel-Schetter, C., Delongis, A., \& Gruen, R. J. (1986). Dynamics of a stressful encounter: Cognitive appraisal, coping, and encounter outcomes. Journal of Personality and Social Psychology, 50, 992-1003.

Gavranidou, M., \& Rosner, R. (2003). The weaker sex? Gender and post-traumatic stress disorder. Depression and Anxiety, 17, 130-139.

Hamilton, S., \& Fagot, B. I. (1988). Chronic stress and coping styles: A comparison of male and female undergraduates. Journal of Personality and Social Psychology, 55(5), 819-823.

Jose, P. E., \& Ratcliffe, V. (2004). Stressor frequency and perceived intensity as predictors of internalizing symptoms: Gender and age differences in adolescence. New Zealand Journal of Psychology, 33(3), 145-154.

Kelly, M. A. R., Sereika, S. M., Battista, D. R., \& Brown, C. (2007). The relationship between beliefs about depression and coping strategies: Gender differences. British Journal of Clinical Psychology, 46, 315-332.

Kessler, R. C., Chiu, W. T., Demler, O., \& Walters, E. E. (2005). Prevalence, severity, and comorbidity of twelve-month DSM-IV disorders in the National Comorbidity Survey Replication (NCS-R). Archives of General Psychiatry, 62(6), 617-27.

Kessler, R. C., \& McLeod, J. D. (1984). Sex differences in vulnerability to undesirable life events. American Sociological Review 49, 620-631.

Matheny, K. B., Ashby, J. S., \& Cupp, P. (2005). Gender differences in stress, coping, and illness among college students. The Journal of Individual Psychology, 61(4), 365-379.

Matud, M. P. (2004). Gender differences in stress and coping styles. Personality and Individual Differences, 37, 1401-1415.

McDonough, P., \& Walters, W. (2001). Gender and health: Reassessing patterns and explanations. Social Science \& Medicine, 52 , 547-559.

Miller, S. M., \& Kirsch, N. (1987). Sex differences in cognitive coping with stress. In R. C. Barnett, L. Biener, \& G. K. Baruch (Eds.), Gender \& stress (pp. 278-307). New York: The Free Press.

Mirowsky, J., \& Ross, C. E. (1995). Sex differences in distress: Real or artifact? American Sociological Review, 60, 449-468.

Mullis, R. L., \& Chapman, P. (2000). Age, gender, and self-esteem differences in adolescent coping styles. The Journal of Social Psychology, 140(4), 539-541.

Pritchard, M. E., \& Wilson, G. S. (2006). Do coping styles change during the first semester of college? The Journal of Social Psychology, 146(1), 125-127.

Renner, M. J., \& Mackin, R. S. (1998). A life stress instrument for classroom use. Teaching of Psychology, 25(1), 46-48. 
Schmaus, B. J., Laubmeier, K. K., Boquiren, V. M., Herzer, M., \& Zakowski, S. G. (2008). Gender and stress: Differential psychophysiological reactivity to stress reexposure in the laboratory. International Journal of Psychophysiology, 69, 101-106.

Sigmon, S. T., Stanton, A. L., \& Snyder, C. R. (1995). Gender differences in coping: A further test of socialization and role constraint theories. Sex Roles, 33, 565-587.

Stein, J. A., \& Nyamathi, A. (1999). Gender differences in relationships between stress, coping, and health risk behaviors in impoverished, minority populations. Personality and Individual Differences, 26, 141-157.

Striegel-Moore, R., Rosselli, F., Perrin, N., DeBar, L., Wilson, G., May, A., \& Kraemer, H. C. (2009). Gender differences in the prevalence of eating disorder symptoms. International Journal of Eating Disorders, 42(5), 471-474.

Topping, W. W. (1990). Success over distress. Bellingham, W.A.: Toping International Institute.

Turner, R. J., Wheaton, B., \& Lloyd, D. A. (1995). The epidemiology of social stress. American Sociological Review, 60, 194-205.

Wyler, A. R., Masuda, M., \& Holmes, T. H. (1968). Seriousness of illness rating scale. Journal of Psychosomatic Research, 11, 363-374. 